\title{
Hormone Therapy and its Effect on the Prognosis in Breast Cancer Patients
}

\author{
Hormonersatztherapie und ihr Effekt auf die Prognose \\ bei Brustkrebspatientinnen
}

Authors

Affiliations
C. Rauh ${ }^{1 *}$, F. Schuetz ${ }^{2 *}$, B. Rack ${ }^{3}$, E. Stickeler ${ }^{4}$, M. Klar ${ }^{4}$, M. Orlowska-Volk ${ }^{5}$, M. Windfuhr-Blum ${ }^{6}$, J. Heil' ${ }^{2}$, J. Rom ${ }^{2}$, C. Sohn ${ }^{2}$, U. Andergassen ${ }^{3}$, J. Jueckstock ${ }^{3}$, T. Fehm ${ }^{7}$, C. R. Loehberg ${ }^{1}$, A. Hein ${ }^{1}$, R. Schulz-Wendtland ${ }^{9}$, A. Hartmann ${ }^{8}$, M. W. Beckmann ${ }^{1}$, W. Janni ${ }^{10}$, P. A. Fasching ${ }^{1,11}$, L. Häberle ${ }^{1,12}$

The affiliations are listed at the end of the article.

\section{Key words \\ - breast cancer \\ - hormone therapy \\ - hormone receptors \\ prognosis \\ Schlüsselwörter \\ - Brustkrebs \\ - Hormontherapie \\ - Hormonrezeptoren \\ - Prognose}

received $\quad 2.5 .2015$ revised $\quad 2.5 .2015$ accepted 19.5.2015

Bibliography

DOI http://dx.doi.org/

10.1055/s-0035-1546149

Geburtsh Frauenheilk 2015; 75 :

588-596 @ Georg Thieme

Verlag KG Stuttgart · New York . ISSN 0016-5751

\section{Correspondence}

Peter A. Fasching, MD

Department of Gynecology and Obstetrics

University Hospital Erlangen

Friedrich-Alexander University

Erlangen-Nuremberg

Universitätsstraße 21-23

91054 Erlangen

peter.fasching@uk-erlangen.de

\section{Abstract \\ $\nabla$}

Introduction: Use of hormone therapy (HT) has declined dramatically in recent years. Some studies have reported that HT use before a diagnosis of breast cancer (BC) may be a prognostic factor in postmenopausal patients. This study aimed to examine the prognostic relevance of HT use before $\mathrm{BC}$ diagnosis.

Methods: Four BC cohort studies in Germany were pooled, and 4492 postmenopausal patients with HT use data were identified. Patient data and tumor characteristics were compared between users and nonusers, along with overall survival (OS), distant metastasis-free survival (DMFS), and local recurrence-free survival (LRFS). Cox proportional hazards models were stratified by study center and adjusted for age at diagnosis, tumor stage, grading, nodal status, and hormone receptors.

Results: Women with HT use before the diagnosis of $\mathrm{BC}$ were more likely to have a lower tumor stage, to be estrogen receptor-negative, and to have a lower grading. With regard to prognosis there were effects seen for OS, DMFS and LRFS, specifically in the subgroup of women with a positive hormone receptor. In these subgroups, BC patients had a better prognosis with previous HT use.

Conclusions: HT use before a diagnosis of BC is associated with a more favorable prognosis in women with a positive hormone receptor status. It may be recommended that the prognostic factor HT should be documented and analyzed as a confounder for prognosis in studies of postmenopausal hormone-responsive breast cancers.

\section{Zusammenfassung \\ $\nabla$}

Einleitung: Der Einsatz einer menopausalen Hormonersatztherapie (HT) hat in den letzten Jahren deutlich abgenommen. Einige kleinere Studien konnten zeigen, dass der Gebrauch vor der Diagnose eines Brustkrebses (BC) ein prognostischer Faktor bei postmenopausalen Patientinnen darstellt. Ziel dieser Studie ist es, die prognostische Relevanz des Hormontherapie-Gebrauchs vor Brustkrebsdiagnose zu untersuchen.

Methoden: Vier Kohortenstudien mit Brustkrebspatientinnen aus Deutschland wurden zusammengefügt, und 4492 postmenopausale Patientinnen, zu denen Daten zum HT Gebrauch vorliegen, konnten identifiziert werden. Patientinnenund Tumorcharakteristika wurden zwischen Patientinnen mit HT zum Diagnosezeitpunkt und Patientinnen ohne HT-Einnahme zum Diagnosezeitpunkt verglichen, zusätzlich das Gesamtüberleben (OS), das fernmetastasenfreie Überleben (DMFS) und das lokalrezidivfreie Überleben (LRFS). Cox-Modelle wurden nach Studienzentren stratifiziert und für Alter bei Diagnose, Tumorstadium, Grading, Nodalstatus und Hormonrezeptorstatus adjustiert.

Ergebnisse: Patientinnen, welche eine HT vor Brustkrebsdiagnose eingenommen hatten, wurden eher mit einem niedrigeren Tumorstadium, einem östrogenrezeptornegativen Tumor und einem niedrigeren Grading diagnostiziert. In Bezug auf die Prognose konnten Effekte bezüglich des OS, DMFS und LRFS, im speziellen in der Subgruppe der Frauen mit einem hormonrezeptorpositiven Tumor gezeigt werden. In diesen Subgruppen hatten Brustkrebspatientinnen, welche zuvor eine HT eingenommen hatten, eine bessere Prognose.

\footnotetext{
* These authors contributed equally to this study.
} 


\begin{tabular}{ll}
\multicolumn{2}{l}{ Abbreviations } \\
ATAC & Arimidex, Tamoxifen, alone or in Combination trial \\
BC & Breast cancer \\
BIG & Breast International Group \\
BMI & Body mass index \\
CI & Confidence interval \\
DMFS & Distant disease-free survival \\
ER & Estrogen receptor \\
HER2 & Human epidermal growth factor receptor 2 \\
HR & Hazard ratio \\
HT & Hormone therapy \\
LRFS & Local recurrence-free survival \\
OS & Overall survival \\
PR & Progesterone receptor \\
US & United States
\end{tabular}

\section{Introduction}

7

Treatment decisions in breast cancer (BC) patients are mainly based on prognostic factors, most of which involve the stage, while others concern with tumor biology [1]. Despite having an effect on tumor biology and possibly prognosis, only few epidemiological factors, like age, are taken into consideration for therapy decisions [2,3]. However, there might be a link between factors that are involved in etiology and pathogenesis on one side and the tumor biology and the prognosis on the other side $[4,5]$. Reproductive factors and body mass index (BMI) seem to have an influence on the risk of mainly hormone receptor-positive tumors [3,6-8], and mammographic density seems to have a greater influence on the risk for estrogen receptor-negative tumors [9, $10]$ and seems to have different effects in women with high and low proliferative tumors [2]. Some genetic factors are linked to hormone receptor-positive others to hormone receptor-negative tumors [11-14]. A genetic susceptibility locus that is a confirmed breast cancer risk factor was shown to have an influence on breast cancer specific survival after the onset of the disease [15]. These data gave us reason to investigate another important breast cancer risk factor with regards to its effect on prognosis, menopausal hormone therapy (HT).

Use of HT is a clear risk factor for the development of postmenopausal BC [16-19]. HT use has been reported to be associated with hormone receptor-positive tumors in some studies [20,21], although other studies have not identified such an association $[22,23]$.

Tumors that develop under the influence of HT have also been found to have a better grade [24-26]. Some studies have reported smaller tumors in groups of patients receiving HT before the development of the cancer $[22,27]$. There have been suggestions that previous HT use is more likely to lead to lobular cancers [21, $27,28]$, but these data are not clear, as the effect was not observed in other studies [20]. The Women's Health Initiative Study found that BC developing during HT was more likely to be HER2 positive (14 vs. 9\%) [23].

As it is known that previous HT intake modifies the risk for specific molecular types of $\mathrm{BC}$, the question of whether this has an effect on the prognosis is logical. Several studies have reported that mortality in patients with BC who are current HT users is lower than in women never taking HT. Patients who developed BC during current HT use developed low-grade tumors and had a better BC-specific survival; in addition, combined HT (estrogen plus progestin) was superior to estrogen alone [29,30]. A better overall survival (OS) among women who were current users of HT at the time of diagnosis has also been reported in a study of women with a positive family history of $\mathrm{BC}$ [31]. One study investigated distant disease-free survival (DMFS) as a measure of the disease's metastatic activity and reported a favorable effect of previous HT intake on DMFS [32].

It has been hypothesized that this effect on the OS might be related to a selection bias, as HT users may have better general health [33], are better informed about and more aware of health issues, and have a healthier lifestyle and better access to healthcare providers. Better surveillance and earlier detection of tumors at an earlier stage has been suggested as another reason for better OS rates.

The aim of this study was to evaluate the influence of HT on overall, distant metastasis-free and local recurrence-free survival in addition to well-known prognostic factors.

\section{Methods \\ $\nabla$}

\section{Patients}

This study is a multicentric, retrospective study, including 4 German certified breast centers (Erlangen, Munich, Freiburg, Heidelberg). Each of these centers contributed original data from cohort studies, for which information about HT use, patient and tumor characteristics and follow-up was available. Inclusion criteria were a diagnosis of invasive BC and postmenopausal status, defined as having been amenorrheal for at least 12 months, amenorrheal status following surgical removal of both ovaries, or age over 55 with unknown menopausal status. Approval for the studies was obtained from local ethics committees at each university hospital.

\section{Data collection and patient treatment}

All participating breast centers are certified by the German Cancer Society and by the German Society for the Study of Diseases of the Breast (Deutsche Gesellschaft für Senologie). To obtain certification, a breast center has to document each BC case prospectively, including patient and tumor characteristics, treatment data, and epidemiological data. As part of the certification, it is checked whether treatment decisions are recommended in accordance with the German guidelines for the treatment of BC. This ensures fairly homogeneous treatment for $\mathrm{BC}$ patients across several institutions. Follow-up information has to be provided for up to 10 years after the primary diagnosis. Additionally, all histological data have to be documented - such as tumor-size, axillary lymph-node status, grading, estrogen receptor (ER) status, progesterone receptor (PR) status, and HER2/neu status. As part of the continuous certification process, the data quality are audited or re-audited annually [34]. Data available from this process were used in the analysis presented here.

Information about HT usage in the patient's history was collected from the patients' charts. Mammography results at the time of the diagnosis were also checked; as hormone therapy is documented as part of the standard mammography procedure. Two variables relating to $\mathrm{HT}$ use were documented: $\mathrm{HT}_{\text {curr }}$ (current HT use at the time of diagnosis, yes or no) and $\mathrm{HT}_{\text {ever }}$ (HT use at any time before the diagnosis, yes or no). 


\section{Statistical analysis}

The primary objective was to study whether HT status information is a prognostic factor for OS, DMFS, and LRFS in addition to well-known prognostic factors. For this purpose, Cox proportional hazards regression analyses as described below were carried out with OS, DMFS, and LRFS, respectively, as outcome and the following predictors: age at diagnosis (continuous), pT (ordinal), ER (positive vs. negative), PR (positive vs. negative), grading (ordinal), nodal status (positive vs. negative), chemotherapy (yes vs. no), and anti-hormone therapy (yes vs. no).

OS was defined as the time interval from the date of initial diagnosis to either the date of death or the date of censoring. Patients who were lost to follow-up within 10 years after diagnosis were censored at the last date they were known to be alive. A patient who was alive 10 years after diagnosis (maximal observation time) was censored at this date. DMFS was defined from the date of initial diagnosis to diagnosis of distant metastasis or the date of censoring. Patients who were lost to follow-up within the maximal observation time were censored at the last date known to be distant metastasis-free. Patients who died within the maximal observation time were censored at the date of death. Patients who were distant metastasis-free after the maximal observation time were censored at this date. LRFS was assessed analogously. Patients with missing outcome and patients with missing HT information were excluded. Missing predictor values were imputed using single "best guesses" (median value of continuous or integer predictors, the most common value of categorical or ordinal predictors) based on non-missing data across all subjects. Continuous predictors were used as natural cubic spline functions to describe non-linear effects [35]. The number of degrees of freedom (between one and five) of each predictor was determined by first fitting several simple cubic spline Cox regression models which differ from each other by the number of degrees of freedom, and then choosing the number of degrees of freedom which optimizes the Akaike information criterion (AIC). The AIC was used because it measures goodness of fit and also takes over-fitting into account by penalizing complex models.

The main survival analysis started with a Cox regression model with the well-known prognostic factors described above but without HT (base model). Next, another Cox model was fitted containing HT, the prognostic factors from the base model and the interactions of these prognostic factors with HT (full model). Both models were compared using the likelihood ratio test. A significant test results means that HT information improved the survival prognosis additionally to the considered well-known prognostic factors either across all patients or at least within one of the subgroups defined by the interaction terms. In case of a nonsignificant result, no further analyses were carried out to avoid false-positive results. If, however, the p-value was significant, then the following variable selection procedure was performed to identify predictors which are associated with HT regarding survival: 1000 bootstrap samples of the same size as the original dataset were taken with replacement from the original dataset. On each bootstrap sample, the full Cox model as defined above was fitted. A backward stepwise variable selection which kept all the predictors of the base model was carried out to obtain the best model in accordance with the AIC. The selected variables from each bootstrap sample were recorded, and a final variable selection was made by applying a procedure proposed by Sauerbrei and Schumacher [36]. In this procedure, the most frequently selected $(>70 \%)$ variables were chosen, and, to address correlation among variables, the variable with the larger frequency out of each highly frequent variable pair (>90\%) was chosen too. A Cox regression model with these finally selected variables was fitted to the original dataset (final model). Due to the selection conditions, the final model necessarily contained all the predictors of the base model and additionally, it possibly contained HT but no interaction term or possibly HT and at least one interaction term. Repetitive variable selections were carried out to get a stable stepwise regression result [37].

The final model was used to calculate adjusted hazard ratios (HRs) with 95\% confidence intervals. An overall HR representing the average prognostic effect of HT across all subgroups as well as HRs representing the average prognostic effect of HT within subgroups were shown. The fact that the study was multi-centric was taken into account by stratifying the models by study center, i.e., different baseline hazard functions were estimated for each study center. Interesting findings were illustrated using cubic spline and Kaplan-Meier curves.

The proportional hazards assumptions were checked using the method of Grambsch and Therneau [38]. If the proportional hazards assumptions had not been fulfilled, the analysis was repeated separately for survival time up to 5 years and from 5 years on.

The performance of the final Cox models in terms of discrimination and calibration ("goodness of fit") was measured with the area under the receiver operating characteristic curve (AUC) for survival data [39] and the modified Hosmer-Lemeshow statistic for survival data originally proposed by Gronnesby and Borgan (1996) [40] and later simplified by May and Hosmer (1998) [41]. The AUC ranges from 0.5 (no discrimination at all) to 1 (perfect discrimination at any time point between patients with event already and patients without event then). Following Gronnesby and Borgan, the observed number of events and the model-based estimated number of events within deciles of predicted risk were compared using a goodness of fit $\mathrm{X}^{2}$ test. A large $\mathrm{p}$-value indicates a satisfactory calibration.

All of the tests were two-sided, and a p-value $<0.05$ was regarded as statistically significant. Calculations were carried out using the $\mathrm{R}$ system for statistical computing (version 3.0.1; R Development Core Team, Vienna, Austria, 2013).

\section{Results}

$\nabla$

\section{Patient and tumor characteristics}

In the 4 cohorts, 4492 out of 5653 postmenopausal patients with invasive $\mathrm{BC}$ were identified for whom information about $\mathrm{HT}_{\text {ever }}$ and survival was available. The percentage of missing values in each prediction variable was below $4 \%$ except of grading (8.0\%). The missing values were imputed as described above to get 4492 complete observations for the $\mathrm{HT}_{\text {ever }}$ analyses. Of those, 1380 (30.7\%) patients had ever used HT. HT users were younger and more often had a lower tumor stage, a lower grade, less often chemotherapy and less often anti-hormone therapy. The hormone receptors ER and PR were similar distributed among patients with and without HT usage. Detailed patient characteristics are shown in 0 Table 1. The median follow-up time was 5.3 years for overall survival, and 4.6 years both for disease-free and local recurrence-free survival. During the follow-up period, 817 deaths, 509 distant metastases and 332 local recurrences were observed.

Information on current use of HT was not available in the Heidelberg cohort $(n=764)$ reducing the sample size in the HT current 
Table 1 Patient and tumor characteristics and association with $\mathrm{HT}_{\text {ever, }}$ showing mean and standard deviation (SD) for age at diagnosis and frequency and percentage for all other data.

\begin{tabular}{|c|c|c|c|c|c|}
\hline Characteristic & Value & $\begin{array}{l}\text { HT no } \\
\text { mean or } n\end{array}$ & $\begin{array}{l}\text { HT no } \\
\text { SD or \% }\end{array}$ & $\begin{array}{l}\text { HT yes } \\
\text { mean or } n\end{array}$ & $\begin{array}{l}\text { HT yes } \\
\text { SD or \% }\end{array}$ \\
\hline Age at diagnosis (year) & & 63.8 & 10.2 & 60.6 & 7.7 \\
\hline \multirow[t]{5}{*}{ pT } & pT0/Tis & 21 & 0.7 & 5 & 0.4 \\
\hline & pT1 & 1703 & 54.7 & 889 & 64.4 \\
\hline & pT2 & 1145 & 36.8 & 410 & 29.7 \\
\hline & PT3 & 102 & 3.3 & 37 & 2.7 \\
\hline & PT4 & 141 & 4.5 & 39 & 2.8 \\
\hline \multirow[t]{2}{*}{ Nodal status } & pNO & 1953 & 62.8 & 931 & 67.5 \\
\hline & $\mathrm{pN}+$ & 1159 & 37.2 & 449 & 32.5 \\
\hline \multirow[t]{3}{*}{ Grading } & G1 & 368 & 11.8 & 191 & 13.8 \\
\hline & G2 & 2020 & 64.9 & 929 & 67.3 \\
\hline & G3 & 724 & 23.3 & 260 & 18.8 \\
\hline \multirow[t]{2}{*}{ ER } & ER- & 703 & 22.6 & 324 & 23.5 \\
\hline & ER+ & 2409 & 77.4 & 1056 & 76.5 \\
\hline \multirow[t]{2}{*}{ PR } & PR- & 1103 & 35.4 & 462 & 33.5 \\
\hline & $\mathrm{PR}+$ & 2009 & 64.6 & 918 & 66.5 \\
\hline \multirow[t]{2}{*}{ Chemotherapy } & no & 2070 & 66.5 & 986 & 71.4 \\
\hline & yes & 1042 & 33.5 & 394 & 28.6 \\
\hline \multirow[t]{2}{*}{ Antihormonal therapy } & no & 1157 & 37.2 & 566 & 41.0 \\
\hline & yes & 1955 & 62.8 & 814 & 59.0 \\
\hline
\end{tabular}

Table 2 Bootstrap-based Cox regression analyses ${ }^{1}$ of $\mathrm{HT}_{\text {ever, }}$, showing inclusion frequencies ${ }^{2}$ (percent) in 1000 bootstrap samples and final selection (yes/no) according to pre-specified criteria.

\begin{tabular}{|c|c|c|c|c|c|c|c|c|}
\hline \multirow{2}{*}{$\begin{array}{l}\text { Predictor }^{3} \\
\mathrm{HT}_{\text {ever }}\end{array}$} & \multicolumn{2}{|c|}{$\begin{array}{l}\text { OS (0-5 } \\
\text { years, \%) }\end{array}$} & \multicolumn{2}{|c|}{$\begin{array}{l}\text { OS (5-10 } \\
\text { years, \%) }\end{array}$} & \multicolumn{2}{|c|}{$\begin{array}{l}\text { DMFS (0-5 } \\
\text { years, \%) }\end{array}$} & \multicolumn{2}{|c|}{$\begin{array}{l}\text { LRFS (0-10 } \\
\text { years, \%) }\end{array}$} \\
\hline & 100.0 & yes & 100.0 & yes & 99.4 & yes & 100.0 & yes \\
\hline $\mathrm{HT}_{\text {ever }} \times \mathrm{PR}$ & 76.6 & yes & 38.0 & no & 56.4 & no & 30.5 & no \\
\hline $\mathrm{HT}_{\text {ever }} \times \mathrm{ER}$ & 70.9 & yes & 86.8 & yes & 32.3 & no & 78.9 & yes \\
\hline $\mathrm{HT}_{\text {ever }} \times$ age & 58.8 & no & 77.5 & yes & 77.7 & yes & 31.1 & no \\
\hline $\mathrm{HT}_{\text {ever }} \times$ chemotherapy & 49.7 & no & 29.2 & no & 46.6 & no & 17.8 & no \\
\hline $\mathrm{HT}_{\text {ever }} \times$ antihormonal therapy & 35.9 & no & 68.9 & no & 26.6 & no & 22.0 & no \\
\hline $\mathrm{HT}_{\text {ever }} \times$ grading & 28.7 & no & 23.5 & no & 21.6 & no & 33.5 & no \\
\hline $\mathrm{HT}_{\text {ever }} \times \mathrm{pN}$ & 28.1 & no & 25.3 & no & 20.2 & no & 42.3 & no \\
\hline $\mathrm{HT}_{\text {ever }} \times \mathrm{pT}$ & 20.8 & no & 40.2 & no & 67.2 & no & 17.6 & no \\
\hline
\end{tabular}

1 There were no selection procedures for DMFS at the second period (5-10 years) because of non-significant result of the likelihood ratio test comparing the base model with the full interaction model.

2 Inclusion frequency may be regarded as a measure of variable importance.

3 The other predictors of the full Cox model (i.e., PR, ER, ..., PT) were kept in all bootstrap samples.

analyses to 3728 patients. Of those, 592 (13.2\%) patients were current users of HT. Patient and tumor characteristics in this subsample were distributed similar to the whole sample (data not shown).

\section{Survival analyses}

The survival analyses had to be carried out separately for the first 5 years and the second 5 years of the follow-up period for overall survival and for distant metastasis-free survival, as the proportional hazards assumptions were fulfilled for the whole followup period only for local recurrence-free survival. The preliminary survival analysis showed that the continuous predictor age was fitted best as a cubic spline variable with 2, 4, 4, 2, and 2 degrees of freedom for OS ( $0-5$ years), OS ( $5-10$ years), DMFS ( $0-5$ years), DMFS (5-10 years), and LRFS, respectively. The performance of the final models, which were discussed below, seemed to be quite good with AUC values between 0.74 and 0.78 for OS and DMFS, and 0.66 and 0.69 for LRFS. The p-values of the Hosmer-Leme- show tests ranged from 0.40 to 0.97 indicating satisfactory calibrations.

\section{$\mathrm{HT}_{\text {ever }}$ and overall survival}

In relation to the first 5 years of follow-up, the multiple Cox survival analysis showed that the prognosis can be improved overall by taking HT into account ( $\mathrm{p}<0.01$, likelihood ratio test comparing the base model with the full interaction model). The most frequent selected interactions at the repetitive variable selection process were HT by PR (77\%) and HT by ER (71\%) resulting in a final Cox regression model with $\mathrm{HT}$, these interactions and the prognostic factors from 0 Table 1 . All other interaction terms were selected in less than $60 \%$ of all bootstrap samples. The percent frequencies are listed in $\bullet$ Tables 2 and 3. These frequency values may be regarded as a measure of variable importance. On average - i.e., without examining specific subgroups - HT users had a better overall survival prognosis than non-users (HR 0.71; 95\% CI 0.57-0.89). However, the benefit differed between 
Table 3 Bootstrap-based Cox regression analyses ${ }^{1}$ of $\mathrm{HT}_{\text {current }}$, showing inclusion frequencies ${ }^{2}$ (percent) in 1000 bootstrap samples and final selection (yes/ no) according to pre-specified criteria.

\begin{tabular}{|c|c|c|}
\hline \multirow{2}{*}{$\begin{array}{l}\text { Predictor }^{3} \\
\mathrm{HT}_{\text {current }}\end{array}$} & \multicolumn{2}{|c|}{$\begin{array}{l}\text { LRFS (0-10 } \\
\text { years, \%) }\end{array}$} \\
\hline & 100.0 & yes \\
\hline $\mathrm{HT}_{\text {current }} \times \mathrm{ER}$ & 74.1 & yes \\
\hline $\mathrm{HT}_{\text {current }} \times$ age & 63.9 & no \\
\hline $\mathrm{HT}_{\text {current }} \times \mathrm{PR}$ & 42.2 & no \\
\hline $\mathrm{HT}_{\text {current }} \times \mathrm{pN}$ & 37.3 & no \\
\hline $\mathrm{HT}_{\text {current }} \times$ grading & 36.5 & no \\
\hline $\mathrm{HT}_{\text {current }} \times$ antihormonal therapy & 29.9 & no \\
\hline $\mathrm{HT}_{\text {current }} \times \mathrm{p} \mathrm{T}$ & 23.5 & no \\
\hline $\mathrm{HT}_{\text {current }} \times$ chemotherapy & 16.9 & no \\
\hline \multicolumn{3}{|c|}{$\begin{array}{l}\text { There were no selection procedures for OS and DMFS because of non-signifi } \\
\text { results of the likelihood ratio tests comparing the base model with the full ir } \\
\text { action model. } \\
\text { Inclusion frequency may be regarded as a measure of variable importance. } \\
\text { The other predictors of the full Cox model (i.e., ER, age, ..., chemotherapy) } \\
\text { were kept in all bootstrap samples. }\end{array}$} \\
\hline
\end{tabular}

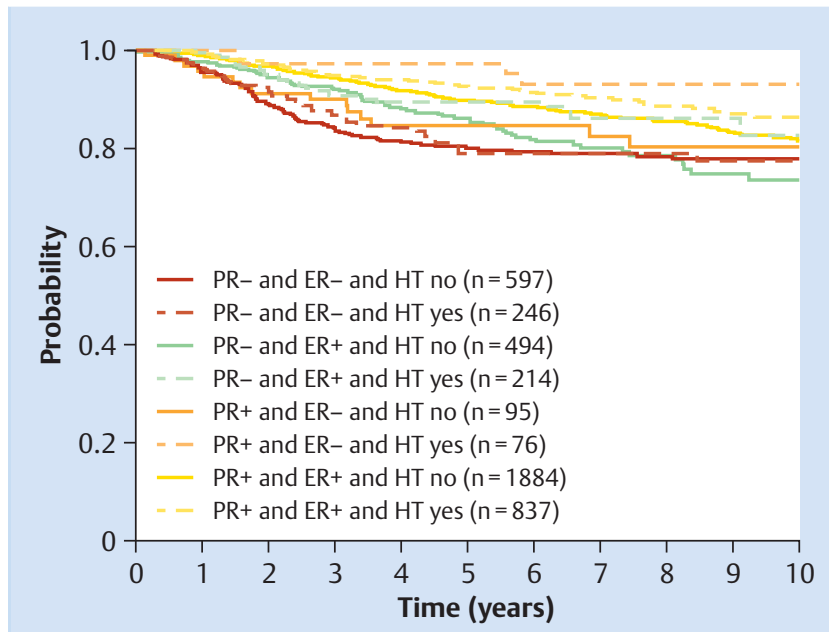

Fig. 1 Overall survival, showing Kaplan-Meier curves for $\mathrm{HT}_{\text {ever }}$ and $\mathrm{PR}$ and ER.

Table 4 Final Cox regression models, showing subgroup specific as well as overall hazard ratios (HRs) for HT ever ("yes" vs. "no") and associated 95\% confidence intervals.

\begin{tabular}{|c|c|c|c|c|c|}
\hline Predictor & & OS ( $0-5$ years) & OS (5-10 years) & DMFS ( $0-5$ years) & LRFS ( $0-10$ years) \\
\hline \multirow[t]{2}{*}{ PR } & PR- & $0.95(0.70,1.29)$ & $--^{2}-1$ & $-^{2}$ & $--^{2}-1$ \\
\hline & $\mathrm{PR}+$ & $0.54(0.37,0.78)$ & - & - & - \\
\hline \multirow[t]{2}{*}{ ER } & ER- & $0.59(0.40,0.87)$ & $0.76(0.34,1.73)$ & $--^{2}$ & $0.74(0.48,1.14)$ \\
\hline & ER+ & $0.86(0.64,1.16)$ & $0.39(0.19,0.77)$ & - & $0.42(0.29,0.60)$ \\
\hline \multirow[t]{3}{*}{$\mathrm{Age}^{1}$} & low (55 years) & -2 & $0.60(0.33,1.09)$ & $0.60(0.42,0.87)$ & -2 \\
\hline & middle (62 years) & - & $0.54(0.28,1.06)$ & $0.89(0.57,1.39)$ & - \\
\hline & high (71 years) & - & $0.85(0.45,1.60)$ & $1.07(0.66,1.74)$ & - \\
\hline Overall & & $0.71(0.57,0.89)$ & $0.54(0.28,1.06)$ & $0.89(0.57,1.39)$ & $0.56(0.42,0.74)$ \\
\hline
\end{tabular}

1 Age was regarded as continuous predictor. It was evaluated at the 20th percentile ("low"), the median ("middle"). and the 80th percentile ("high").

2 There are no subgroup specific HRs for this predictor, because the corresponding interaction term was dropped during the variable selection process.

patient groups. Patients with a PR-positive tumor and an ER-negative tumor benefited from HT usage (HR 0.44; 95\% CI 0.25-0.77) as well as patients with a PR-positive and ER-positive tumor (HR 0.65; 95\% CI 0.47-0.89), whereas an influence of HT on survival could not be shown for patients with an PR-negative tumor both for ER-negative patients (HR 0.70; 95\% CI 0.56-1.11) and for ERpositive patients (HR 1.15; 95\% CI 0.73-1.81). Briefly, PR-positive patients generally benefited, ER-negative patients only benefited if they were PR-positive. Summarized HRs for ER-subgroups and PR-subgroups are shown in $\triangle$ Table 4. Crude survival rates are shown in 0 Fig. 1.

HT also had prognostic value after 5 years of follow-up $(p=0.02$, likelihood ratio test). The finally selected interaction terms were HT by ER (87\%) and HT by age (78\%). The most important interaction term among those which were not selected was HT by antihormonal therapy with $69 \%$ selection frequency ( Table 2 ). Patients with an ER-positive tumor benefited from HT but patients with an ER-negative tumor did not ( $\bullet$ Table 4). The prognosis curves in Fig. 2 shows that patients with HT had the best survival prognosis at the age around 60, an effect which could not be seen in patients without HT. Moreover, the difference between HT users and non-users is largest at this age apart from the eldest patients, what, however, should be considered with caution because of competitive risks of elder people.
$\mathrm{HT}_{\text {ever }}$ and distant metastasis-free survival

HT proved to be a significant additional predictor in the first period but not in the second period, according to likelihood ratio tests comparing base models and full models $(\mathrm{p}=0.03$ and $\mathrm{p}=0.60)$.

The interaction between age and HT was the only selected interaction term in the analysis of the first period having a frequency of $78 \%$ (Table 4). Patients with HT had the best metastasis-free prognosis at an age between 55 and 60 years, whereas patients without HT had a peak 5 years later. The difference between HT users and non-users is largest between 55 and 60. There are hardly any differences after 65 years ( $\bullet$ Fig. 3 ).

\section{$\mathrm{HT}_{\text {ever }}$ and local recurrence-free survival}

HT significantly improved the prognosis throughout the total observation time ( $p<0.001$, likelihood ratio test). ER-positive patients who took HT seemed to live longer local recurrence-free than ER-positive patients who did not take a HT. No effect could be shown for ER-negative patients ( Table 4, Fig. 4)

\section{$\mathrm{HT}_{\text {current }}$}

We could not show that HT information improved prognosis additionally to the considered well-known prognostic factors with regard to overall survival $(\mathrm{p}=0.24$ and $\mathrm{p}=0.08$ ) and distant me- 


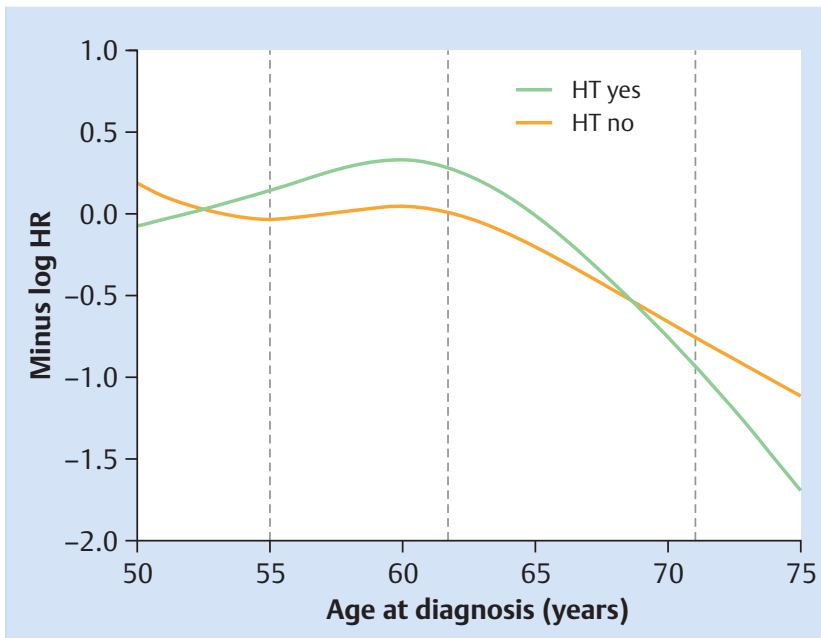

Fig. 2 Overall survival prognosis between 5 and 10 years after diagnosis in $\mathrm{HT}_{\text {ever }}$ users and non-users relative to their age at diagnosis. The results (in terms of log hazard ratio with HT "no" and 62 years as reference) are based on the final Cox regression model with age as cubic spline function adjusted for the prognostic factors in 0 Table 1 . The higher the value on the $y$-axis, the better the survival prognosis. The log hazard ratio (HR) for HT users vs. non-users for patients with a specific age can be read by fixing the age value and subtracting the associated $y$-values on the green and orange curves. The grey vertical lines indicate the 20th, 50th, and 80th percentile of age.

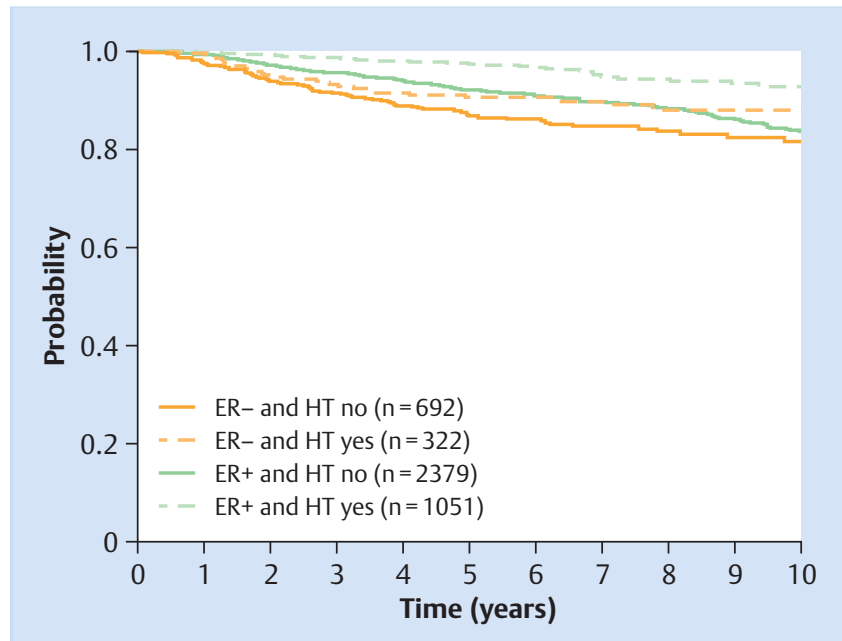

Fig. 4 Local recurrence-free survival, showing Kaplan-Meier curves for $\mathrm{HT}_{\text {ever }}$ and ER.

tastasis-free survival ( $\mathrm{p}=0.45$ and $\mathrm{p}=0.48$ ) according to likelihood ratio tests comparing regression models in survival analyses of the first 5 years and the last 5 years of follow-up. But HT information improved the prognosis of local recurrence-free survival ( $p<0.001$, likelihood ratio test). The results of subsequent analyses were similar to those of $\mathrm{HT}_{\text {ever }}$. Patients with an ER-positive tumor benefited from HT (HR 0.28; 95\% CI 0.16-0.51), whereas no effect of HT could be shown in patients with an ERnegative tumor (HR 0.75; 95\% Cl 0.43-1.31) (O Fig. 5).

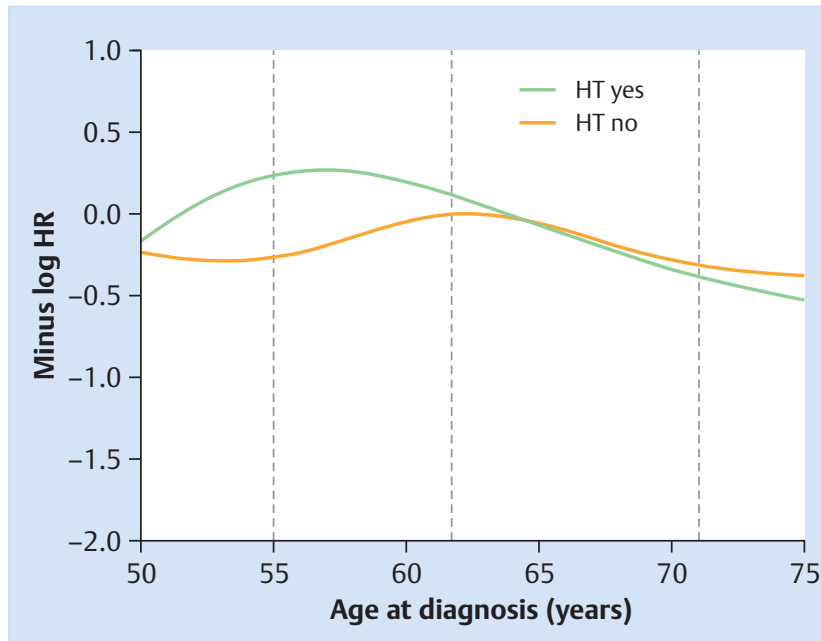

Fig. 3 Distant metastasis-free survival prognosis up to 5 years after diagnosis in $\mathrm{HT}_{\text {ever }}$ users and non-users relative to their age at diagnosis. The results (in terms of log hazard ratio with HT "no" and 62 years as reference) are based on the final Cox regression model with age as cubic spline function adjusted for the prognostic factors in $\odot$ Table 1 . The higher the value on the $y$-axis, the better the survival prognosis. The log hazard ratio (HR) for HT users vs. non-users for patients with a specific age can be read by fixing the age value and subtracting the associated $y$-values on the green and orange curves. The grey vertical lines indicate the 20th, 50th, and 80th percentile of age.

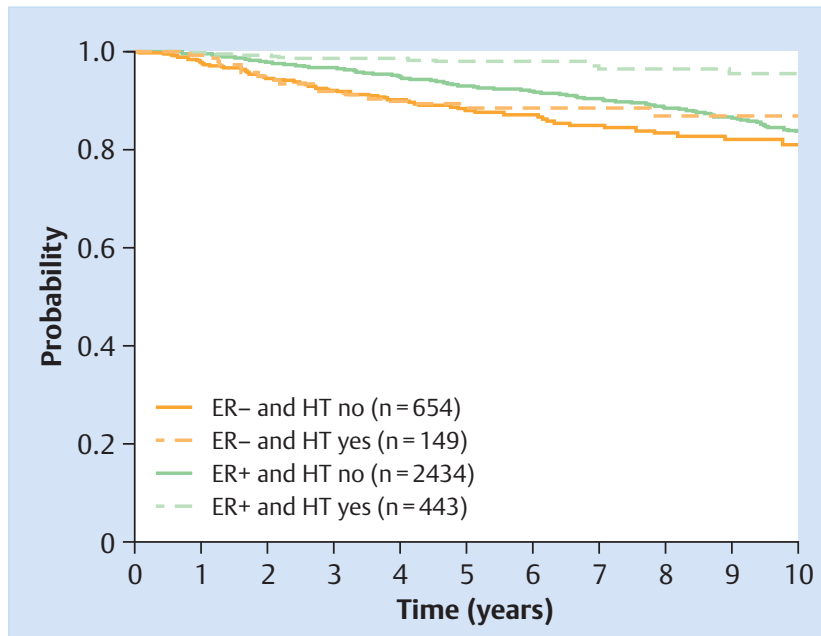

Fig. 5 Local recurrence-free survival, showing Kaplan-Meier curves for $\mathrm{HT}_{\text {current }}$ and $\mathrm{ER}$.

\section{Discussion}

This multicenter, retrospective cohort study showed that intake of HT has an influence on overall-survival resulting in a better overall survival prognosis compared to non-users. However, the benefit differed between patient groups. Briefly, PR-positive patients generally benefited, whereas a prognostic effect could not be shown for PR-negative patients. ER-negative patients only benefited if they were PR-positive. Additionally interesting interactions with covariates were found, especially with age at diagnosis. 
Several previous studies have demonstrated an effect of previous HT use on overall or BC-specific survival $[24,28,29,33,42,43]$, although others did not observe this effect [44]. Some studies also studied the effect of HT on prognosis in ovarian cancer patients [5]. There has been debate as to whether the effect is caused by earlier detection due to better compliance among HT users taking part in early detection programs, or by an effect of HT that results in tumors with a more favorable phenotype with regard to hormone receptor status, or a better grading. Most of these associations, (HT was associated with pT, pN, ER, and G) were also observed in our study. However we included these factors as confounders into our analysis.

A report from the Women's Health Initiative (WHI) trial not only provided data for the effect of estrogen plus progestin on the cumulative $\mathrm{BC}$ incidence, but also for the first time provided data on BC mortality in a prospectively randomized study [45]. The increased breast cancer risk, as has been reported previously in this placebo-controlled trial, was confirmed with a mean follow-up period of 11 years (HR 1.25; 95\% CI 1.07-1.46) [45]. In addition, the survival analysis for BC patients showed increased BC-related mortality in the group receiving estrogen plus progestin (HR 1.96; 95\% CI 1.00-4.05). However, the survival analysis for the report started with randomization for the WHI study, rather than at the onset of the diagnosis of $\mathrm{BC}$, and the total number of events was low at 25 vs. $12 \mathrm{BC}$-related deaths. The survival analysis was not adjusted for breast cancer incidence and other tumor-related prognostic factors. It is therefore difficult to compare the results with existing data about the influence of HT on prognosis and with the present study, that are more meant to discover clinically relevant and independent prognostic factors. That we have identified subgroups of breast cancer patients where the effect of a previous HT use has a specific effect on the prognosis might suggest that the effects that were seen in the WHI study might be attributable to a subgroup of patients as well.

In our study the strongest association with HT as a prognostic factor was seen in PR-positive women in the first 5 years after the diagnosis. This is of specific interest as HT has been shown to increase the risk for breast cancer only or specifically for women who use HT that contains estrogens and progestin [19]. The risk for breast cancer does not seem to be increased when only estrogens are taken, as it was shown in the women's health initiative study in the group of patients who were hysterectomized [46]. Furthermore it has been shown that women who take combined estrogen and progestin HT develop more likely a hormone receptor-positive, especially progesterone receptor-positive tumors [20]. Therefore it might be postulated that especially in the group of progesterone receptor-positive women a distinct biological effect - like prognosis - might be most prevalent in women with a hormone receptor-positive tumor. Furthermore, it might be hypothesized that women who develop a breast cancer tumor under HT, which is PR-positive, might be the group of women, who most likely benefit from a cessation of HT and the use of antihormonal therapy.

Recently a large study on a similar patient collective as ours showed that PR status can improve prediction of survival outcome regarding OS, DMFS and LRFS, patients with PR-positive tumors had a better overall survival prognosis than PR-negative patients (HR 0.61; 95\% CI 0.48-0.76) [47]. This prognostic effect of PR status seemed to decrease with increasing age. Similar to that in our study the effect of HT as a prognostic factor became smaller with increasing age and with regard to DMFS the HR increased from 0.60 in the group of women around 55 years of age to 1.07 in women around 71 years of age. A similar effect was seen with regard to OS.

There are only few studies on prognostic factors concerning local recurrence after a diagnosis of invasive breast cancer [48]. Age, lymph node status and tumor size are the predominant factors. The integration of new, molecular markers seems to be too complex to be integrated into clinical practice [48]. Although we cannot provide data on the use of radiotherapy the size of the effect of HT on the local recurrence is so great that it is reasonable to assume that previous HT might have an influence on local recurrence independently of the radiotherapy used. Therefore previous HT use seems to be reasonable to consider as an influencing factor for subsequent local recurrences after a diagnosis of invasive breast cancer.

The use of HT has declined dramatically in recent years. In the US, the percentage of women who receive HT for menopausal symptoms has decreased by $38 \%$ since 2002 , with approximately 20 million fewer prescriptions in 2003 than in 2002 [49]. In Germany, HT use similarly declined from $44.9 \%$ in 2001 to $14.6 \%$ in 2006 [50].

The effect of previous HT use on the prognosis is clearest in hormone receptor-positive women, implying that HT use might be a major confounder for the prognosis in this patient group. In fact, most of the clinical trials that provide evidence for treatment decisions are based on studies in which a relevant percentage of patients were receiving $\mathrm{HT}$ at the time of the diagnosis. In the ATACTrial, 35.5\% of women were documented as having current HT use at the time of the diagnosis [51], while in the BIG 1-98 study, it was $39.3 \%$ [52]. HT might also be a confounder in those studies on antihormonal treatment. If it is hypothesized that the effect of antihormonal treatment is greater in the group of previous HT users, the effect might prove to be smaller in the subgroup of patients who were not taking HT at the time of the diagnosis or had never received it previously. Similar considerations could apply to the interpretation of previous studies on radiotherapy and local recurrence of the $\mathrm{BC}$, given the substantial effects of previous HT use on the risk of local recurrence. However, these hypotheses have to be tested within the respective studies.

The present study has several strengths and weaknesses. Strengths include its large sample size and multicenter nature. The findings were obtained after a stratified analysis of data from the participating study centers and were found consistently for the several outcomes of OS, DMFS, and LFRS. However, the multicenter design also involves some weaknesses. The study is retrospective, and the data were therefore collected heterogeneously in all the participating hospitals. The major difficulties are the study's design and the lack of data for BC-specific survival. It is therefore difficult, but not impossible, to conclude that the effects of HT on the DMFS and LRFS lead to a reduction in the mortality rate. The interactions especially with the PR status imply that the effects should have to do something with the tumor biology. In addition, data about the patients' HT status was obtained from medical records, and it might be hypothesized that HT use was not fully documented for every patient. In Germany, however, $\mathrm{BC}$ is treated by gynecologists (with surgery and chemotherapy). In the centers participating in the study, a question regarding HT use was therefore included in the standard questionnaire completed by each patient treated at the centers. Data regarding the duration of HT use were unfortunately not available from every study center. 


\section{Conclusion}

\section{$\nabla$}

HT use before the diagnosis of breast cancer has an effect on the prognosis after diagnosis. It may be recommended that previous HT use should be documented in future BC studies concerned with antihormonal treatment and/or local recurrence.

\section{Acknowledgements}

$\nabla$

We are grateful to Michael Robertson for professional English editing services.

\section{Conflict of Interest}

\section{$\nabla$}

The authors declare that they have no competing interests.

\section{Affiliations}

${ }^{1}$ University Breast Center, Department of Gynecology and Obstetrics, Erlangen University Hospital, Comprehensive Cancer Center EMN, Erlangen

2 Breast Unit, Department of Gynecology and Obstetrics, Heidelberg University Hospital

${ }^{3}$ Department of Gynecology and Obstetrics, Campus Innenstadt University Hospital, Ludwig Maximilian University, Munich

${ }^{4}$ Department of Obstetrics and Gynecology, Freiburg University Medical Center, Freiburg

${ }^{5}$ Institute of Pathology, Freiburg University Medical Center, Freiburg

${ }^{6}$ Department of Radiology, Freiburg University Medical Center, Freiburg

7 Department of Gynecology and Obstetrics, Duesseldorf University Hospital, Düsseldorf

${ }^{8}$ Institute of Pathology, University Breast Center, Erlangen University Hospital, Comprehensive Cancer Center EMN, Erlangen

${ }^{9}$ Institute of Diagnostic Radiology, University Breast Center,

Erlangen University Hospital, Comprehensive Cancer Center EMN, Erlangen

10 Department of Gynecology and Obstetrics, Ulm University Hospital, Ulm

11 Department of Medicine, Division of Hematology and Oncology, David Geffen School of Medicine, University of California at Los Angeles, USA

12 Biostatistics Unit, Department of Gynecology and Obstetrics, Erlangen University Hospital, Erlangen

\section{References}

1 Lux MP, Maass N, Schutz F et al. Breast cancer 2013 - interpretation of new and known data. Geburtsh Frauenheilk 2013; 73: 584-598

2 Eisemann N, Waldmann A, Katalinic A. Epidemiology of breast cancer current figures and trends. Geburtsh Frauenheilk 2013; 73: 130-135

3 Rauh C, Gass P, Heusinger $K$ et al. Association of molecular subtypes with breast cancer risk factors: a case-only analysis. Eur J Cancer Prev 2014; DOI: 10.1097/CEJ.0000000000000111

4 Fasching PA, Ekici AB, Adamietz BR et al. Breast cancer risk - genes, environment and clinics. Geburtsh Frauenheilk 2011; 71: 1056-1066

5 Fasching PA, Ekici AB, Wachter DL et al. Breast cancer risk - from genetics to molecular understanding of pathogenesis. Geburtsh Frauenheilk 2013; 73: 1228-1235

6 Althuis MD, Fergenbaum JH, Garcia-Closas M et al. Etiology of hormone receptor-defined breast cancer: a systematic review of the literature. Cancer Epidemiol Biomarkers Prev 2004; 13: 1558-1568

7 Hess KR, Pusztai L, Buzdar AU et al. Estrogen receptors and distinct patterns of breast cancer relapse. Breast Cancer Res Treat 2003; 78: 105118

8 Yang XR, Chang-Claude J, Goode EL et al. Associations of breast cancer risk factors with tumor subtypes: a pooled analysis from the Breast Cancer Association Consortium studies. J Natl Cancer Inst 2011; 103: 250-263

9 Heusinger K, Jud SM, Haberle L et al. Association of mammographic density with hormone receptors in invasive breast cancers: Results from a case-only study. Int J Cancer 2012; 131: 2643-2649

10 Yaghjyan L, Colditz GA, Collins LC et al. Mammographic breast density and subsequent risk of breast cancer in postmenopausal women according to tumor characteristics. J Natl Cancer Inst 2011; 103: 11791189
11 Broeks A, Schmidt MK, Sherman ME et al. Low penetrance breast cancer susceptibility loci are associated with specific breast tumor subtypes: findings from the Breast Cancer Association Consortium. Hum Mol Genet 2011; 20: 3289-3303

12 Milne RL, Benitez J, Nevanlinna $\mathrm{H}$ et al. Risk of estrogen receptor-positive and -negative breast cancer and single-nucleotide polymorphism 2q35-rs13387042. J Natl Cancer Inst 2009; 101: 1012-1018

13 Stevens KN, Vachon CM, Lee AM et al. Common breast cancer susceptibility loci are associated with triple-negative breast cancer. Cancer Res 2011; 71: 6240-6249

14 Stevens KN, Fredericksen Z, Vachon CM et al. 19p13.1 is a triple-negative-specific breast cancer susceptibility locus. Cancer Res 2012; 72: 1795-1803

15 Fasching PA, Pharoah PD, Cox A et al. The role of genetic breast cancer susceptibility variants as prognostic factors. Hum Mol Genet 2012; 21: 3926-3939

16 Beral $V$. Breast cancer and hormone-replacement therapy in the Million Women Study. Lancet 2003; 362: 419-427

17 Chlebowski RT, Kuller LH, Prentice RL et al. Breast cancer after use of estrogen plus progestin in postmenopausal women. N Engl J Med 2009; 360: 573-587

18 Collaborative Group on Hormonal Factors in Breast Cancer. Breast cancer and hormone replacement therapy: collaborative reanalysis of data from 51 epidemiological studies of 52,705 women with breast cancer and 108,411 women without breast cancer. Lancet 1997; 350: 10471059

19 Rossouw JE, Anderson GL, Prentice RL et al. Risks and benefits of estrogen plus progestin in healthy postmenopausal women: principal results From the Women's Health Initiative randomized controlled trial. JAMA 2002; 288: 321-333

20 Ursin G, Tseng CC, Paganini-Hill A et al. Does menopausal hormone replacement therapy interact with known factors to increase risk of breast cancer? J Clin Oncol 2002; 20: 699-706

21 Stahlberg C, Pedersen AT, Andersen ZJ et al. Breast cancer with different prognostic characteristics developing in Danish women using hormone replacement therapy. Br J Cancer 2004; 91: 644-650

22 Holli K, Isola J, Cuzick J. Low biologic aggressiveness in breast cancer in women using hormone replacement therapy. J Clin Oncol 1998; 16: 3115-3120

23 Chlebowski RT, Anderson GL, Gass $M$ et al. Breast cancer outcome and estrogen plus progestin use in postmenopausal women. J Clin Oncol 2010; Suppl.; Abstr. 1507

24 Schairer C, Gail M, Byrne C et al. Estrogen replacement therapy and breast cancer survival in a large screening study. J Natl Cancer Inst 1999; 91: 264-270

25 Bonnier P, Bessenay F, Sasco AJ et al. Impact of menopausal hormonereplacement therapy on clinical and laboratory characteristics of breast cancer. Int J Cancer 1998; 79: 278-282

26 Esteve J, Seradour B, Jacquemier J et al. Does a better grade of tumour occurring in women under hormone replacement therapy compensate for their lower probability of detection by screening mammography. J Med Screen 2002; 9: 70-73

27 Daling JR, Malone KE, Doody DR et al. Association of regimens of hormone replacement therapy to prognostic factors among women diagnosed with breast cancer aged 50-64 years. Cancer Epidemiol Biomarkers Prev 2003; 12: 1175-1181

28 Fletcher AS, Erbas B, Kavanagh AM et al. Use of hormone replacement therapy (HRT) and survival following breast cancer diagnosis. Breast 2005; 14: 192-200

29 Bergkvist L, Adami HO, Persson I et al. Prognosis after breast cancer diagnosis in women exposed to estrogen and estrogen-progestogen replacement therapy. Am J Epidemiol 1989; 130: 221-228

30 Rosenberg LU, Granath F, Dickman PW et al. Menopausal hormone therapy in relation to breast cancer characteristics and prognosis: a cohort study. Breast Cancer Res 2008; 10: R78

31 Sellers TA, Mink PJ, Cerhan JR et al. The role of hormone replacement therapy in the risk for breast cancer and total mortality in women with a family history of breast cancer. Ann Intern Med 1997; 127: 973-980

32 Schuetz F, Diel IJ, Pueschel M et al. Reduced incidence of distant metastases and lower mortality in 1072 patients with breast cancer with a history of hormone replacement therapy. Am J Obstet Gynecol 2007; 196: 342.e1-342.e9

33 Marshall SF, Chang E, Clarke CA et al. Hormone therapy use before diagnosis and breast cancer survival in the California teachers study. Cancer Res 2009; 69: Abstract \#65 
34 Beckmann MW, Brucker C, Hanf V et al. Quality assured health care in certified breast centers and improvement of the prognosis of breast cancer patients. Onkologie 2011; 34: 362-367

35 Harrell FE jr., Lee KL, Pollock BG. Regression models in clinical studies: determining relationships between predictors and response. J Natl Cancer Inst 1988; 80: 1198-1202

36 Sauerbrei $W$, Schumacher $M$. A bootstrap resampling procedure for model building: application to the Cox regression model. Stat Med 1992; 11: 2093-2109

37 Simon R, Altman DG. Statistical aspects of prognostic factor studies in oncology. Br J Cancer 1994; 69: 979-985

38 Grambsch PM, Therneau TM. Proportional hazards tests and diagnostics based on weighted residuals. Biometrika 1994; 81: 515-526

39 Chambless LE, Diao G. Estimation of time-dependent area under the ROC curve for long-term risk prediction. Stat Med 2006; 25: 34743486

40 Gronnesby JK, Borgan O. A method for checking regression models in survival analysis based on the risk score. Lifetime Data Anal 1996; 2: 315-328

41 May S, Hosmer DW. A simplified method of calculating an overall goodness-of-fit test for the Cox proportional hazards model. Lifetime Data Anal 1998; 4: 109-120

42 Fowble B, Hanlon A, Freedman $G$ et al. Postmenopausal hormone replacement therapy: effect on diagnosis and outcome in early-stage invasive breast cancer treated with conservative surgery and radiation. J Clin Oncol 1999; 17: 1680-1688

43 Rosenberg $L U$, Einarsdottir K, Friman EI et al. Risk factors for hormone receptor-defined breast cancer in postmenopausal women. Cancer Epidemiol Biomarkers Prev 2006; 15: 2482-2488
44 Yuen J, Persson I, Bergkvist L et al. Hormone replacement therapy and breast cancer mortality in Swedish women: results after adjustment for 'healthy drug-user' effect. Cancer Causes Control 1993; 4: 369-374

45 Chlebowski RT, Anderson GL, Gass M et al. Estrogen plus progestin and breast cancer incidence and mortality in postmenopausal women. JAMA 2010; 304: 1684-1692

46 Anderson GL, Limacher M, Assaf AR et al. Effects of conjugated equine estrogen in postmenopausal women with hysterectomy: the Women's Health Initiative randomized controlled trial. JAMA 2004; 291: 17011712

47 Salmen J, Neugebauer J, Fasching PA et al. Pooled analysis of the prognostic relevance of progesterone receptor status in five German cohort studies. Breast Cancer Res Treat 2014; 148: 143-151

48 van der Leij F, Elkhuizen PH, Bartelink $H$ et al. Predictive factors for local recurrence in breast cancer. Semin Radiat Oncol 2012; 22: 100-107

49 Ravdin PM, Cronin KA, Howlader $N$ et al. The decrease in breast-cancer incidence in 2003 in the United States. N Engl J Med 2007; 356: 16701674

50 Katalinic A, Stegmaier C, Rawal R et al. Less hormone replacement therapy, less breast cancer in Germany? Geburtsh Frauenheilk 2007; 67: 1217-1221

51 Baum M, Budzar AU, CuzickJ et al. Anastrozole alone or in combination with tamoxifen versus tamoxifen alone for adjuvant treatment of postmenopausal women with early breast cancer: first results of the ATAC randomised trial. Lancet 2002; 359: 2131-2139

52 Thurlimann B, Keshaviah A, Coates AS et al. A comparison of letrozole and tamoxifen in postmenopausal women with early breast cancer. N Engl J Med 2005; 353: 2747-2757 